REGULAR ARTICLE

\title{
RAPD CHARACTERIZATION OF PSEUDOMONAS SPECIES IDENTIFIED FROM CLINICAL SAMPLES
}

\section{RAJARAJAN PETHANNAN ${ }^{*}$, AMUDHA CHINNAIAH KUPPUSWAMY ${ }^{2}$, RAJANI GUPTA ${ }^{1}$, KIRUBAKARAN VINOD KUMAR ${ }^{1}$, SWATI BALIYAN, GURU PRASAD, VRASHABHA JAWAI ${ }^{1}$}

1Department of Microbiology, Center for Research and PG Studies, Indian Academy Degree College-Autonomous, Hennur Cross, Kalyan Nagar, Bangalore 560043, India

${ }^{2}$ CMR Institute of Management Studies, HRBR Lay Out, Bangalore 560043, India

\begin{abstract}
Pseudomonas aeruginosa is the most common dreadful pathogenic gram negative bacilli responsible for nosocomial infections among hospital patients especially in developing countries. In the present study P. aeruginosa isolated from various clinical samples and evaluated for their variability and genetic relationship using PCR based Randomly Amplified Polymorphic DNA (RAPD) technique. A total of 30 different samples from patients with wounds, ear infection, respiratory tract, nasal infection and urine infection were collected from various hospitals and diagnostic centers in Bangalore. The samples included pus swabs, wound discharge, sputum and blood. These samples were subjected to $P$. aeruginosa isolation using selective media and characterization using biochemical tests. Further genetic relationship was determined using RAPD technique. A total of 7 were isolated and characterized biochemically and identified belonging to $P$. aeruginosa. Cluster analysis and phylogenetic tree reveal close relatedness between $P$. aeruginosa strain $\mathrm{P}_{1}, \mathrm{P}_{3}, \mathrm{P}_{4}, \mathrm{P}_{5}$ and $\mathrm{P} 6$ but distantly related to the $\mathrm{P}_{2}$ and $\mathrm{P}_{7}$. This indicates that the infection due to $P$. aeruginosa is caused by diverse as well as closely related clones circulating in the study health care centers. This demands further investigation through prospective studies with a larger number of patients. This will aid suggesting efficient and sustained control measures and antibiotic policy in study area.
\end{abstract}

Keywords: Pseudomonas aeruginosa, RAPD-PCR, Clinical sample

\section{INTRODUCTION}

Pseudomonas aeruginosa is one among the major opportunistic pathogens from the family Pseudomonaceae residing in part of human mycoflora and can cause many diseases [1]. Nosocomial infections caused by $P$. aeruginosa are a major problem in hospitals due to its intrinsic capacity to acquire resistance to all effective antibiotics $[2,3]$. P. aeruginosa is a leading cause of ventilator-associated pneumonia (VAP) and around 20\% of pneumonia conditions in intensive care units (ICU) [4]. Due to these reasons, it is significant to note the antibiotic resistance in the clinical specimens.

In humans the common source of $P$. aeruginosa isolation are blood, urine, pus, sputum and wounds samples of infected patients [5]. The assessment of the clonal relationship is crucial for determining the epidemiology of nosocomial infections and designing of pathogen control methods $[6,7]$. Previous studies have reported high rate of polymorphism and genetic diversity among $P$. aeruginosa isolates especially in different types of clinical specimens
[8]. In recent years PCR-based molecular genotyping of $P$. aeruginosa has been gained popularity over tedious phenotyping methods in both environment and clinical isolates [9]. Although, different PCR-based genotypic techniques have been described for characterizing $P$. aeruginosa isolates, Random Amplified Polymorphic DNA (RAPD)-PCR has received considerable attention in recent years for studying genetic relatedness. It comprises high strain differentiation power and is a definitive method for molecular characterizing of bacteria [10]. RAPD-PCR can be considered as a powerful tool to reveal extensive DNA polymorphism between the genomes of different species under the same genus [11]. This rapid methodology has been shown to be as discriminatory as Pulsed-field gel electrophoresis (PFGE) for typing $P$. aeruginosa and was recommended for the primary screening of large numbers of isolates because of its efficiency $[6,12]$. The present study was undertaken to isolate and determine the RAPD genotyping of $P$. aeruginosa strains isolated from different clinical samples from hospitals and various diagnostic centers in Bangalore.

Received 17 December 2017; Accepted 14 February 2018

*Corresponding Author

Rajarajan Pethannan

Department of Microbiology, Center for Research and PG Studies, Indian Academy Degree College-Autonomous, Hennur Cross, Kalyan Nagar, Bangalore 560043, India

Email: rajarajanbioscience@gmail.com

(T) This article is open access and licensed under the terms of the Creative Commons Attribution License (http://creativecommons.org/licenses/by/4.o/) which permits unrestricted, use, distribution and reproduction in any medium, or format for any purpose, even commercially provided the work is properly cited. Attribution - You must give appropriate credit, provide a link to the license, and indicate if changes were made. 


\section{MATERIALS METHODS}

\section{Sample collection and isolation of Pseudomonas}

Different 30 clinical specimens were collected, including wound discharge, ear swabs, nasal swabs, blood and urine from patients in hospitals. Blood culture was taken from patients who were suspicious of sepsis. Sputum samples were also collected from patients. The samples were immediately transferred to the laboratory. Pseudomonas was isolated using Cetrimide Agar (Hi-Media, India) a selective and differential medium for Pseudomonas spp. The colony morphology was noted and morphological characterization of bacterial culture was determined using Gram's Staining procedure. The isolates were further subjected to standard biochemical tests including catalase, oxidase, Indole-Methyl red-Voges-Proskauer-Citrate utilization test (IMVIC), casein hydrolysis, nitrate reduction, gelatin hydrolysis, and sugar fermentation [13].

\section{Bacterial DNA extraction}

The isolates were revived and freshly grown in Nutrient broth medium with optimum bacterial growth were subjected to DNA extraction as per the Phenol: Chloroform method described by Sambrook and Russel [14]. The extracted DNA was dissolved in Tris EDTA (TE) buffer and stored at-20 ${ }^{\circ} \mathrm{C}$ for further experiments. The quality and concentration of extracted DNA was determined using NanoDrop ${ }^{\mathrm{TM}} 1000$ Spectrophotometer from Thermo Fisher Scientific.

\section{RAPD fingerprinting assay}

RAPD fingerprinting assay was performed as per standard methodologies $[7,8]$.

\section{RESULTS AND DISCUSSION}

Pseudomonas aeruginosa is the most common dreadful pathogenic gram negative bacilli responsible for nosocomial infections and also as the important cause for morbidity and mortality among hospital patients especially in developing countries [15]. P. aeruginosa has an ability to acquire and harbor diverse resistance determinants. $P$. aeruginosa is a major microorganism which can be resistant to antibiotics causing Multi Drug Resistance (MDR). It remains one of the significant hospital acquired infection worldwide, despite efficient infection control policies [16]. P. aeruginosa is the causing agent of $10 \%-$ $20 \%$ of nosocomial infections [17]. In India, prevalence rate of $P$. aeruginosa infection varies from 2-23\% [18]. Another study form India reports 66.07\% (40/60) patients were found to be infected with $P$. aeruginosa during their stay in hospital, from among which 56 strains were isolated [19].

The present study deals with the determination of genetic diversity among Pseudomonas spp. isolated from clinical samples using RAPD markers. The source of the samples was from wound, pus, blood and urine from patient's in hospitals. The rationale in choosing these sample was based on published literature, on their frequency of $P$. aeruginosa isolation from these sample, some of them are discussed below. Although sputum is an ideal sample for detection of nosocomial infections, sputum often does not provide complete information about the progression of both acute and chronic lung diseases caused by $P$. aeruginosa viz. chronic obstructive pulmonary disease COPD, cystic fibrosis. Blood stream infections is associated with higher mortality rates depending on the patient's conditions [20]. Similar study by Fazeli et al. [21] isolated $P$. aeruginosa strains from clinical specimens including urine (16\%), tracheal (31.2\%), wound (33.3\%), and blood (33.3\%) specimens. Often these isolates are Multi Drug Resistant (MDR). In an another study with a total of 932 clinical samples $P$. aeruginosa was isolated from pus (28.7\%), urine (28.8\%), blood (28.9\%), and sputum (28.6) [22].

In the present study $P$. aeruginosa was isolated from various clinical samples from hospitals and diagnostic centers to study the genetic relatedness among the samples for determination of common source of infection. The Pseudomonas isolates were isolated and purified on Cetrimide Agar plates and was further maintained on Nutrient Agar slants. Totally 8 isolates were recovered from 4 different clinical samples viz, sputum, blood, pus and wound. All the isolates were gram negative, uniformly stained, straight or slightly curved rods, measuring 0.5 to $1.0 \mu \mathrm{m}$ by 1.5 to $5.0 \mu \mathrm{m}$ in length. They were aerobic, nonspore forming, motile bacteria. The isolates appeared fluorescent yellow or green color on Cetrimide agar plates (fig. 1). Further the Pseudomonas strains were subjected to biochemical characterization (table 1). Seven out of eight isolates belonged to $P$. aeruginosa and for one isolate species could not be identified biochemically.

RAPD-PCR have shown to be useful technique to study the genetic variability between bacterial strains, due to its great specificity and sensitivity [23]. This technique has been often used in the case of $P$. aeruginosa widely for different types of clinical and environmental isolates [24]. Moreover, RAPD-PCR could be considered as valuable technique especially in developing countries as a source for tracking the infections since it is cost effective PCR based technique.

In this study, DNA fingerprinting was performed using two RAPD primers (OPA-11 and OP-D20). RAPD has been utilized to type a wide range of bacteria including $P$. aeruginosa and the method described here is proved very useful for discrimination among $P$. aeruginosa isolates. In this study, both the primers OP-A11 and OP-D2O produced clear banding patterns. All the observed bands were polymorphic and no monomorphic bands were observed. The bands obtained ranged between $500 \mathrm{bp}-2 \mathrm{~kb}$. The use of molecular markers to study genetic diversity will help in characterizing the Pseudomonas spp. isolated from clinical samples. The cluster analysis and phylogenetic tree depending on genetic distance reveal the genetic relationship between the $P$. aeruginosa isolates subjected to RAPD-PCR analysis. This put to rest the fact that there is definitely a high rate of genetic recombination or mutations leading to a high level of genetic diversity among the $P$. aeruginosa isolates population. The UPGMA average cluster analysis of RAPD-PCR banding pattern using OP-A11 primer showed genetic distance values range from 0.23 to 0.15 . The lowest genetic distance of (0.15) was found between $P$. aeruginosa strain 1 and 5 , whereas the highest genetic distance (0.23) was observed between strain 7 and 3 . The phylogenetic tree shows close relatedness between $P$. aeruginosa strain 4, 5, 6 and 1, but is distantly related to the other samples (fig. 2). The UPGMA average cluster analysis of RAPD-PCR banding pattern using OP-A11 primer showed genetic distance values range from 0.24 to 0.14 . The lowest genetic distance of (0.14) was found between isolate 3 and 4 , whereas the highest genetic distance (0.23) was observed between isolate 6 and isolate 7 . The phylogenetic tree shows close 
relatedness between $P$. aeruginosa strain 3 and 4 but distantly related to the other samples (fig. 3). Earlier De Vos et al. [12] and Renders et al. [25] utilized this technique for typing and epidemiological characterization of $P$. aeruginosa strains and described usefulness of the technique in laboratory in combination with other techniques as a tool for managing nosocomial infections $[12,25]$, which was discussed by Nanvazadeh et al. [24] in their paper on typing of $P$. aeruginosa isolates from burn wounds.

Table 1: Morphological and biochemical characterization of the isolates

\begin{tabular}{|c|c|c|c|c|c|c|c|c|c|}
\hline Isolate & $\begin{array}{l}\text { Gram } \\
\text { staining/ } \\
\text { Morphology }\end{array}$ & Arabinose Mannose & Mannitol & $\begin{array}{l}\text { Indole } \\
\text { Test }\end{array}$ & $\begin{array}{l}\text { Methyl } \\
\text { Red } \\
\text { Test }\end{array}$ & $\begin{array}{l}\text { VP } \\
\text { Test }\end{array}$ & $\begin{array}{l}\text { Catalase } \\
\text { Test }\end{array}$ & $\begin{array}{l}\text { Citrate } \\
\text { Utilization } \\
\text { Test }\end{array}$ & $\begin{array}{l}\text { Oxidase } \\
\text { Test }\end{array}$ \\
\hline $\mathrm{P}_{1}$ & Neg. rods & - & - & - & - & - & + & + & + \\
\hline $\mathrm{P} 2$ & Neg. rods & - & - & - & - & - & + & + & + \\
\hline $\mathrm{P}_{3}$ & Neg. rods & - & - & - & - & - & + & + & + \\
\hline $\mathrm{P}_{4}$ & Neg. rods & - & - & - & - & - & + & + & + \\
\hline $\mathrm{P}_{5}$ & Neg. rods & - & - & - & - & - & + & + & + \\
\hline P6 & Neg. rods & - & - & - & - & - & + & + & + \\
\hline $\mathrm{P}_{7}$ & Neg. rods & - & - & - & - & - & + & + & + \\
\hline P8 & Neg. rods & + & + & - & - & - & + & + & + \\
\hline
\end{tabular}

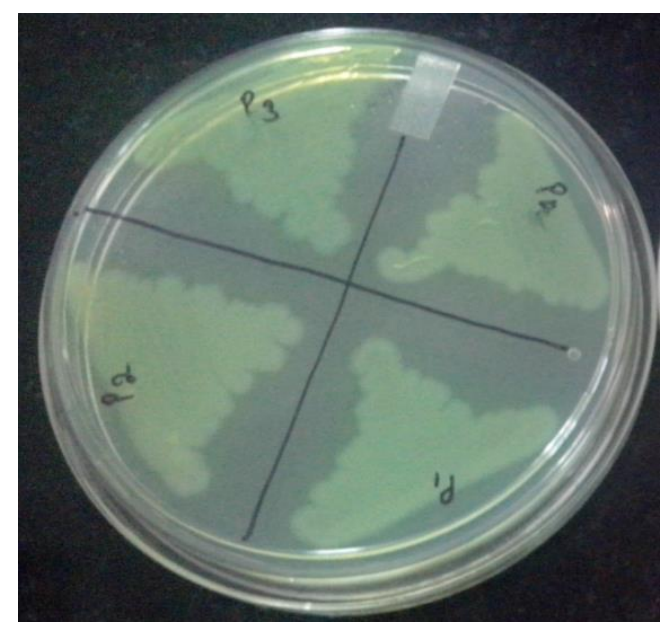

Fig. 1: Subcultured Pseudomonas isolates on cetrimide agar plates

A.

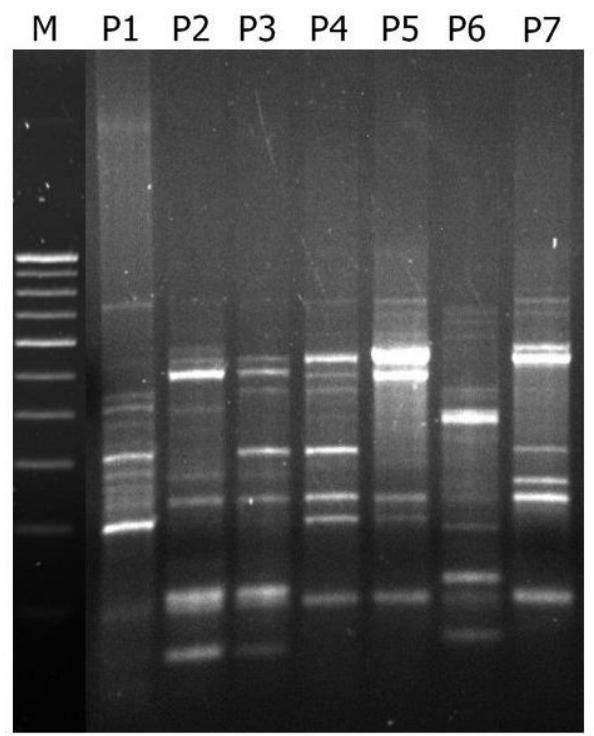

B.
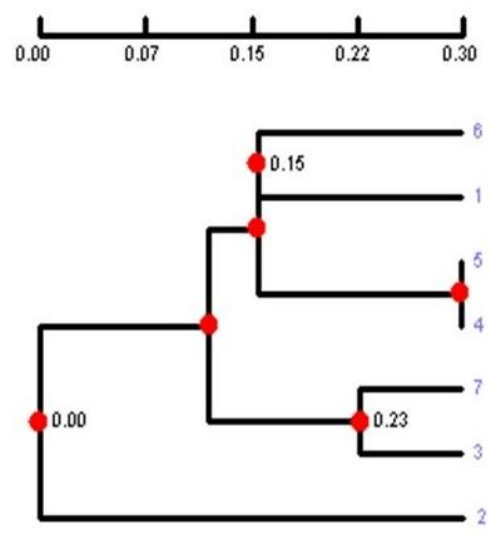

Distance matrix method: Frequency Similarity Cluster method: UPGMA

Matric: Adj Rf Reference: Lane 2 Tolerance: 1.00 \%

Fig. 2: DNA fingerprinting results using OP-A11 primer. A) Agarose gel image showing RAPD-PCR banding pattern. B) The UPGMA average cluster analysis 
A.

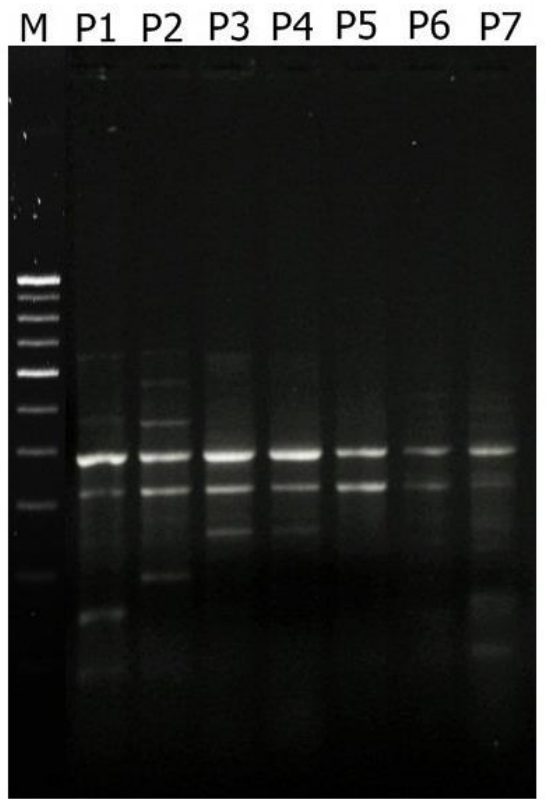

B.

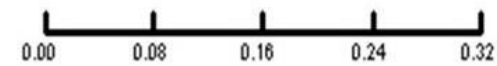

Distance matrix method: Frequency Similarity Cluster method: UPGMA

Metric: Adj Rf Reference: Lane 1 Tolerance: 1.00 \%

Fig. 3: DNA fingerprinting result using OP-D2o primer. A) Agarose gel image showing RAPD-PCR banding pattern. B) The UPGMA average cluster analysis

\section{CONCLUSION}

$P$. aeruginosa have been isolated from different parts of the world with high heterogenic difference, diverse environment factors, therapeutic strategies and level of hospital hygiene has impacted the distribution and genetic clonal formation variation. The present was a primary attempt to isolate $P$. aeruginosa for clinical sample and determine the genetic relatedness among them. Moreover, this study also utilized RAPD-PCR as a reliable tool for typing $P$. aeruginosa in local setting. Further it is necessary to develop prospective studies with a larger number of patients to solve many uncertainties that still exist in such prevalent disease in hospitals. This will aid suggesting efficient and sustained control measures and antibiotic policy in study area.

\section{ACKNOWLEDGMENT}

The authors would like to thank the authorities of both the institutions Indian Academy Degree College and CMR Institute of Management Studies for providing lab facilities.

\section{CONFLICT OF INTERESTS}

Nil

\section{ETHICAL CLEARANCE}

The study is approved by institutional ethical committee.

\section{REFERENCES}

1. Yang L, Jelsbak L, Marvig RL, Damkiaer S, Workman CT, Rau MH, Hansen SK, Folkesson A, Johansen HK, Ciofu O, Hoiby N, Sommer MO, Molin S. Evolutionary dynamics of bacteria in a human host environment. Proc Natl Acad Sci USA 2011;108:7481-7486.

2. Nseir S, Ader F, Lubret R, Marquette $\mathrm{CH}$. Pathophysiology of airway colonization in critically ill COPD patient. Curr Drug Targets 2011;12:514-520.
3. Fuentefria DB, Ferreira AE, Corcao G. Antibiotic resistant Pseudomonas aeruginosa from hospital wastewater and superficial water: are they genetically related? J Environ Manage 2011;92:250-255.

4. Nikbin VS, Aslani MM, Sharafi Z, Hashemipour M, Shahcheraghi F, Ebrahimipour GH. Molecular identification and detection of virulence genes among Pseudomonas aeruginosa isolated from different infectious origins. Iranian J Microbiol 2012;4:118-123.

5. Malini A, Deepa EK, Gokul BN, Prasad SR. Nonfermenting Gram-Negative Bacilli Infections in a Tertiary Care Hospital in Kolar, Karnataka. J Lab Physicians 2009;1:62-66.

6. Fatemeh N, Dokht K. A., Reza Z. M., Najmeh P. Genotyping of Pseudomonas aeruginosa strains isolated from burn patients by RAPD-PCR. Burns 2013;39:1409-1413.

7. Barnini S, Dodi C, Campa M. Enhanced resolution of random amplified polymorphic DNA genotyping of Pseudomonas aeruginosa. Lett App Microbiol 2004;39:274-277.

8. AL-Assie AH, Al-azawy AF, Al-Dori WS. Molecular characterization of Pseudomonas aeruginosa isolates isolated from clinical patients by using RAPD-PCR technique. J Univ Anbar Pure Sci 2012;6:27-35.

9. Singh A, Goering RV, Simjee S, Foley SL, Zervos MJ. Application of molecular techniques to the study of hospital infection. Clin Microbiol Rev 2006;19:512530.

10. Thangaraj M, Prem V, Ramesh T, Lipton AP. RAPD fingerprinting and demonstration of genetic variation in three pathogens isolated from Mangrove environment. Asian J Biotechnol 2011;3:269-274.

11. Vishwanatha T, Jain SN, Reena V, Divyashree BC, Siddalingeshwara KG, Karthic J, Sudipta KM. Screening of substrates for protease production from Bacillus licheniformis. Inter $\mathrm{J}$ Engin Sci Technol 2010;2:6550-6554. 
12. De Vos D, Lim A, Pirnay JP, Duinslaeger L, Revets H, Vanderkelen A, Hamers R, Cornelis P. Analysis of epidemic Pseudomonas aeruginosa isolated by isoelectric focusing of pyoverdine and RAPD-PCR: modern tools for an integrated anti-nosocomial infection strategy in burn wound centres. Burns 1997;23:379-386.

13. Ningthoujam DS, Shovarani N. Isolation and characterization of a Pseudomonas aeruginosa strain DN1 degrading p-nitrophenol. Res J Microbiol 2008;3:345-351.

14. Sambrook J, Russel D. Molecular Cloning: A Laboratory Manual. New York, NY, USA: Cold Spring Harbor Laboratory Press; 2001

15. Nasreen M, Sarker A, Malek M, Ansaruzzaman M, Rahman M. Prevalence and resistance pattern of Pseudomonas aeruginosa isolated from surface water. Advan Microbiol 2015;5: 74-81

16. Khosravi AD, Hoveizavi H, Mohammadian A, Farahani A, Jenabi A. Genotyping of multidrug resistant strains of Pseudomonas aeruginosa isolated from burn and wound infections by ERIC-PCR. Acta Cirurgica Brasileira 2016;31:206-211.

17. Carmeli Y, Troillet N, Eliopoulos GM, Samore MH. Emergence of antibiotic-resistant Pseudomonas aeruginosa: comparison of risks associated with different antipseudomonal agents. Antimicrob Agents Chemother 1999;43:1379-1382.

18. Senthamarai S, Reddy A, Kumar S, Sivasankari S, Anitha C, Somasunder V., Kumudhavathi MS, Amshavathani SK, Venugopal V. Resistance Pattern of Pseudomonas aeruginosa in a Tertiary Care Hospital of Kanchipuram, Tamilnadu, India. J Clin Diagn Res 2014;8:DC30-DC32.

19. Biswal I, Arora BS, Kasana D, Neetushree. Incidence of Multidrug Resistant Pseudomonas Aeruginosa Isolated from Burn Patients and Environment of Teaching Institution. J Clin Diagn Res 2014;8:DC26DC29.

20. Kato I, Fujimoto F, Higurashi Y, Yamaguchi R, Takayama K, Suzuki M, Okugawa S, Okazaki M, Moriya K. Antibiotic susceptibilities of Pseudomonas aeruginosa isolated from blood samples and antibiotic utilization in a university hospital in Japan. Infect Dis Ther 2015;4:213-218.

21. Fazeli H, Akbari R, Moghim S, Narimani T, Arabestani MR, Ghoddousi AR. Pseudomonas aeruginosa infections in patients, hospital means, and personnel's specimens. J Res Med Sci 2012;17:332-337.

22. Adhikari L, Roy K, Tsering DC, Pal R, Kar S. Susceptibility rates of Pseudomonas aeruginosa strains to quinolones. J Lab Physicians 2010;2:121-121.

23. Williams JG, Kubelik AR, Livak KJ, Rafalski JA, Tingey SV. DNA polymorphisms amplified by arbitrary primers are useful as genetic markers. Nucleic Acids Res 1990;18:6531-6535.

24. Nanvazadeh F, Khosravi AD, Zolfaghari MR, Parhizgari N. Genotyping of Pseudomonas aeruginosa strains isolated from burn patients by RAPD-PCR. Burns 2013;39:1409-1413.

25. Renders N, Römling Y, Verbrugh H, van Belkum A. Comparative typing of Pseudomonas aeruginosa by random amplification of polymorphic DNA or pulsedfield gel electrophoresis of DNA macrorestriction fragments. J Clin Microbiol 1996;34:3190-3195. 